\title{
くも膜下出血に対する初期治療の現状と問題点
}

\author{
片岡 大治 ${ }^{1)}$, 中川 俊祐 ${ }^{2)}$, 高橋 淳 ${ }^{2)}$, 高木 康志 ${ }^{3)}$, 宮本 享 ${ }^{1}$ ) \\ 1）京都大学脳神経外科，2）国立循環器病研究セン夕ー脳神経外科，3）徳島大学脳神経外科
}

\section{Current Status of Problems with Initial Treatment for Aneurysmal Sub- arachnoid Hemorrhage}

\author{
Hiroharu Kataoka, M.D., Ph.D. ${ }^{1)}$, Shunsuke Nakagawa, M.D. ${ }^{2)}$, Jun C Takahashi, M.D., Ph.D. ${ }^{2}$, \\ Yasushi Takagi, M.D., Ph.D. ${ }^{3)}$, and Susumu Miyamoto, M.D., Ph.D. ${ }^{1)}$ \\ 1) Department of Neurosurgery, Graduate School of Medicine, Kyoto University, 2) Department of Neurosurgery, National \\ Cerebral and Cardiovascular Center, 3) Department of Neurosurgery, Institute of Biomedical Sciences, Tokushima University \\ Graduate School
}

Subarachnoid hemorrhage (SAH) has a poor prognosis with a mortality rate of $25-50 \%$. Because rerupture is highly associated with mortality, a correct diagnosis must be made as soon as possible and the appropriate initial treatment must be performed. Delayed diagnosis due to failure in obtaining a computed tomography (CT) scan or missed diagnosis of SAH on CT can sometimes results in a fatal outcome. A lumbar puncture or magnetic resonance imaging is necessary to diagnose SAH even after a negative CT scan in cases wherein SAH is suspected based on symptoms. Although there is a general consensus that analgesia, sedation, and blood pressure lowering should be performed in the initial treatment of SAH, for sedation and blood pressure control protocols have not been defined. In cases with a poor-grade SAH, intracranial pressure (ICP) and cardiovascular complications should be properly managed. Placement of an external ventricular drain is recommended for acute hydrocephalus. Three-dimensional computed tomography angiography (3D-CTA) has recently been used for identifying the bleeding source. However, 3D digital subtraction angiography (3D-DSA) is more useful for the decision making between clipping and coiling.

(Received November 28, 2018 ; accepted January 28, 2019)

Key words : subarachnoid hemorrhage, prehospital care, misdiagnosis, initial care, intracranial aneurysm Jpn J Neurosurg（Tokyo）28:542-551, 2019

\section{はじめに}

脳卒中は神経外傷とともにわれわれ脳神経外科医が担 う主要な救急疾患である。その中でもくも膜下出血 （subarachnoid hemorrhage：SAH）は診断や治療が発達し た現在でも死亡率が $25 \sim 50 \%{ }^{16)}$ と最も予後不良な脳卒
中病型であり，臨床の最前線ではSAH 患者の予後改善の ため, 日々懸命な努力が行われている。これまでの prospective population-based studyのメ夕解析によれば, 1973 2002 年までの 30 年間で SAH の死亡率は $17 \%$ 減少 している ${ }^{16)}$. 特に，従来予後不良のため手術適応がない とされてきた Hunt and Hess Grade V の予後は近年改善 
している. Schuss ら ${ }^{20)}$ の報告によれば, 1980〜1995 年の 15 年間では Grade V SAH で modified Rankin Scale (mRS) 0２の予後良好はゼロであったが，2004２014 年の 10 年間では $24 \%$ が mRS 0 2 の予後良好の転帰をとってい た。 また SAH死亡率は地域差が大きく, 欧米のほとんど の国で 40〜 50\%であるのに対して，日本では $30 \%$ 程度 と低い数字が報告されている ${ }^{16)}$. 治療を受けることなく 死亡した症例の多くが除外されているだけであるとの解 釈もあるが，日本の現状を考えると心肺停止状態の最重 症例でも病院に救急搬送され，画像診断や病理解剖など の方法で SAH の診断が得られているケースが多いと思 われる。やはり人口あたりの脳神経外科医の数が多く, 都市部から農村部に至るまで脳神経外科医が 24 時間体 制で骖療を行っているわが国の診療体制と現場の献身的 な努力，診断・治療から術後管理を含めたわが国の脳神 経外科診療のレベルの高さを反映したものであると思わ れる. Abulhasan $~^{1)}$ によると SAH の病院内死亡の原因 は, 初回出血によるダメージが $26.2 \%$, 再出血が $23 \%$, 脳浮腫が $19.7 \%$ と初期診療に関する要因が大きいのがわ かる，さらなるSAHの予後改善のためには，手術成績の 向上や脳血管攣縮治療の進歩も重要であるが，初期診療 の向上も欠くことができない要素である. SAH の初期診 療のポイントを一言でいうと,「いかに再出血を起こす ことなく, 出血源である動脈瘤を閉塞させるか」に尽き る. 本稿では, prehospital care, SAH の的確な診断, 初 期治療，出血源同定など，脳動脈瘤に対する外科治療や 血管内治療を行うまでのSAH患者の管理に関して，その 現状と問題点について述べる.

\section{SAH 患者の搬送時間と搬送経路が 予後に及ぼす影響}

急性心筋梗塞 ${ }^{6}$ や急性脳主幹動脈閉塞 ${ }^{19)}$ においては, 発症から治療までの時間が短いほど予後良好になること が知られており, 救急搬送時間の短縮や治療可能な中核 病院への直接搬送が重要視されている.SAHでは, 搬送 時間や搬送経路が予後に与える影響についてはさまざま な報告があり，一定の見解が得られていない。一般的に は，転院搬送や長時間の搬送は再出血の危険性を高める と考えられるが，米国の診療情報データベースである Nationwide Inpatient Sample を用いて，2002 年から 5 年 間の SAH 患者 47,114 症例について直接搬送群と転院搬 送群の違いを検証した研究では, 両群において予後に差 はみられなかった ${ }^{17)}$ 。一方，比較的大きな単施設からの 報告では，直接搬送群のほうが転院搬送群よりも予後良
好であったという報告もみられる15)。 また, van Lieshout $ら^{25)}$ は, World Federation of Neurosurgical Surgeons (WFNS) Grade Vの重症 SAH においては搬送の遅延が 死亡率の上昇につながると報告しているが, Wilson ら ${ }^{28)}$ の軽症例も含めた解析では差がみられず，とにかく早く 搬送するよりも，状態を安定させてから安全に搬送する ほうがよいという意見が述べられている。

著者らは，国立循環器病研究センターで，救急隊から の救急搬送情報と診療情報を統合した救急搬送デー夕 ベースを作成し，2016 年 4 月～2017 年 11 月までの SAH 救急搬送症例の検討を行った。国立循環器病研究セン ターは，大阪北部郊外の住宅地に存在し，豊中市・吹田 市・箕面市などの約 100 万人の医療圈をカバーしてい る。また同医療圈には，クリッピング・コイリングを 24 時間体制で行うことができる施設が複数存在しており， 手術はできないが CTにて SAH の診断が行える医療施設 は多数存在している。調查期間中に同施設に救急搬送さ れた SAH でデータベースに登録された患者は 94 例（男 性 32 例, 年齢 32 91 歳) で，直接搬送 74 例，転院搬送 20 例であった。搬送時間および搬送経路と退院時 mRS の関係をみると，搬送時間に関しては 30 分以内の群が 30 分以上の群よりも有意に予後良好であったが（Fig. 1A），搬送経路別では転院搬送群の予後がむしろ良好で あつた（Fig. 1B）。転院搬送群について詳しくみると， 直接搬送群と比較して有意に WFNS grade が低く（Fig. 1C), 搬送時収縮期血圧が低い傾向にあった（Fig. 1D）。 以上のデー夕は，重症 $\mathrm{SAH}$ が選択的に同施設にトリアー ジされ，軽症例は他院搬送後 SAH と診断された後に，降 圧や鎮静などの十分な初期加療がされた状態で転院搬送 されてきているという現状を反映している，米国のよう に国土が広大で搬送にヘリコプターなどを使用すること も多い国では，搬送距離は明らかにSAHの予後と相関し ており，わが国でも医療圈が広大な農村山間部において は, SAH 疑いの症例はできるだけすみやかに脳神経外科 医が常駐する専門病院に搬送すべきであると思われる が，人口の密集する都市部においてすべての SAH疑いの 患者を専門病院に搬送するのは非現実的である。都市部 においては，Fig.2のようなトリアージとなることが多 く，軽症例の多くは非専門病院で診断され専門病院に転 送されることになる。この際に重要なのは，初期対応病 院での SAH の確実な診断と診断後の適切な初期治療で ある、今後わが国でも認定されることになる包括的脳卒 中センターにおいては，地域での啓発活動が必須要件と なる見込みであるが，SAH についてはその必要性が特に 高い. 
A

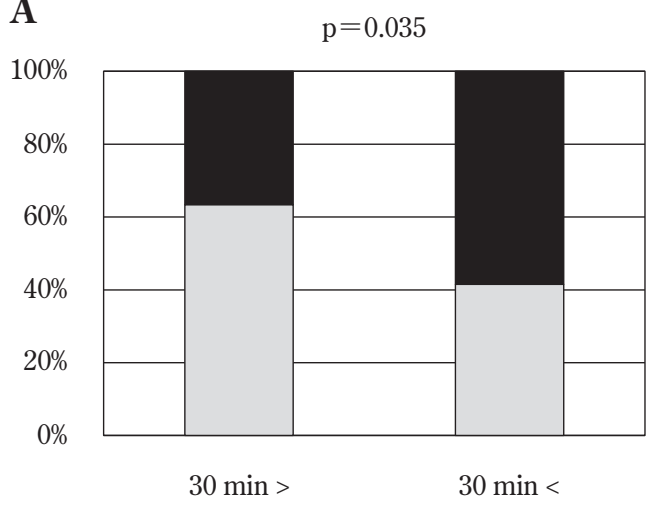

Transport time
B

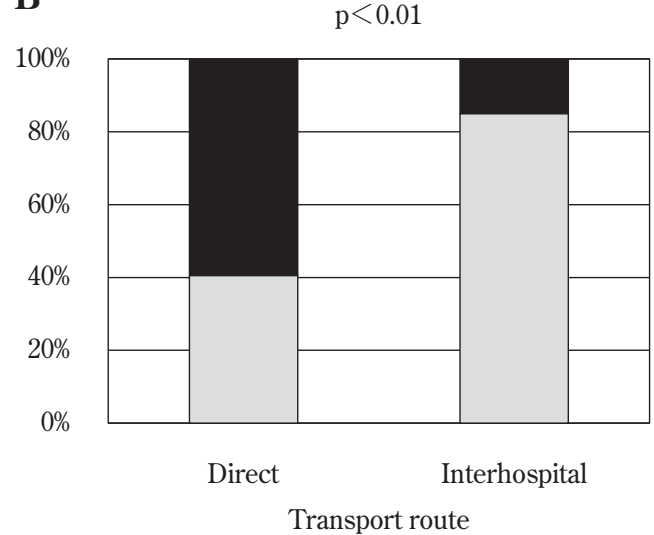

$\square \operatorname{mRS} 0-2 \quad \square$ mRS 3-6

D

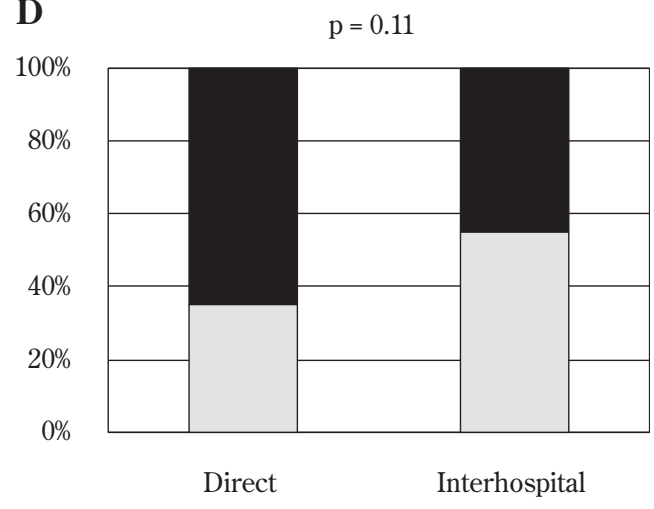

Systolic blood pressure
C

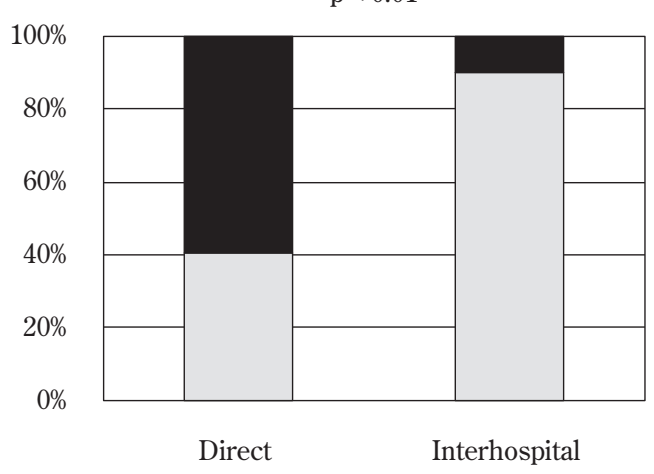

WFNS grade

$\square<160 \quad \boldsymbol{\square} \geqq 160$

Fig. 1 The influence of transport time and transport route on the prognosis of patients with SAH at National Cerebral and Cardiovascular Center

A : The relationship between the modified Rankin Scale ( $\mathrm{mRS}$ ) at discharge and transport time in patients with SAH.

B : The relationship between the mRS at discharge and transport route in patients with SAH.

$\mathrm{C}:$ The ratio of patients with a poor WFNS grade in the direct transfer group compared with the interhospital transfer group.

D : The ratio of patients with good blood pressure control (systolic blood pressure $<160$ $\mathrm{mmHg}$ ) during transfer in the direct transfer group compared with the interhospital transfer group.

\section{初期診療におけるSAH の見逃しと 診断の遅れ}

これまでの報告でもSAHは初回診療において 5 〜 $12 \%$ が正しく診断されておらず，初回診療で正しく診断され なかった SAH は再出血などにより予後不良となる危険 性が指摘されている ${ }^{14) 26)}$. 2014年度に日本脳卒中学会の 事業として高木，宮本らが行った「初期診療で確定診断 されなかったくも膜下出血に関する全国悉皆調査」では, 日本全国の日本脳卒中学会認定教育施設 737 施設に対し て, 2012 年 4 月〜 2014 年 3 月の 2 年間の初期診療で確
定診断されなかった SAH 症例についてのアンケート調 査を行った。その結果，合計 579 例の初期診療で確定診 断されなかった SAH が報告され，うち $27 \%$ に再出血が 起こり，11\%が死亡の転帰をとつた ${ }^{23)}$. 579 例のうち 417 例 $(72 \%)$ が日本脳神経外科学会や日本脳卒中学会の教 育訓練施設以外の診療所や一般病院で診断されており (Fig. 3A)，335 例（58\%）で CT や MRI などの画像検査 が行われていなかった (Fig. 3B)。突然の激しい頭痛か ら SAH を疑い, SAH を疑ったら頭部 CT を行うことは, 脳神経外科医にとっては常識であるが，それを地域の他 科医師や一般開業医に伝えていく重要性を改めて認識さ 


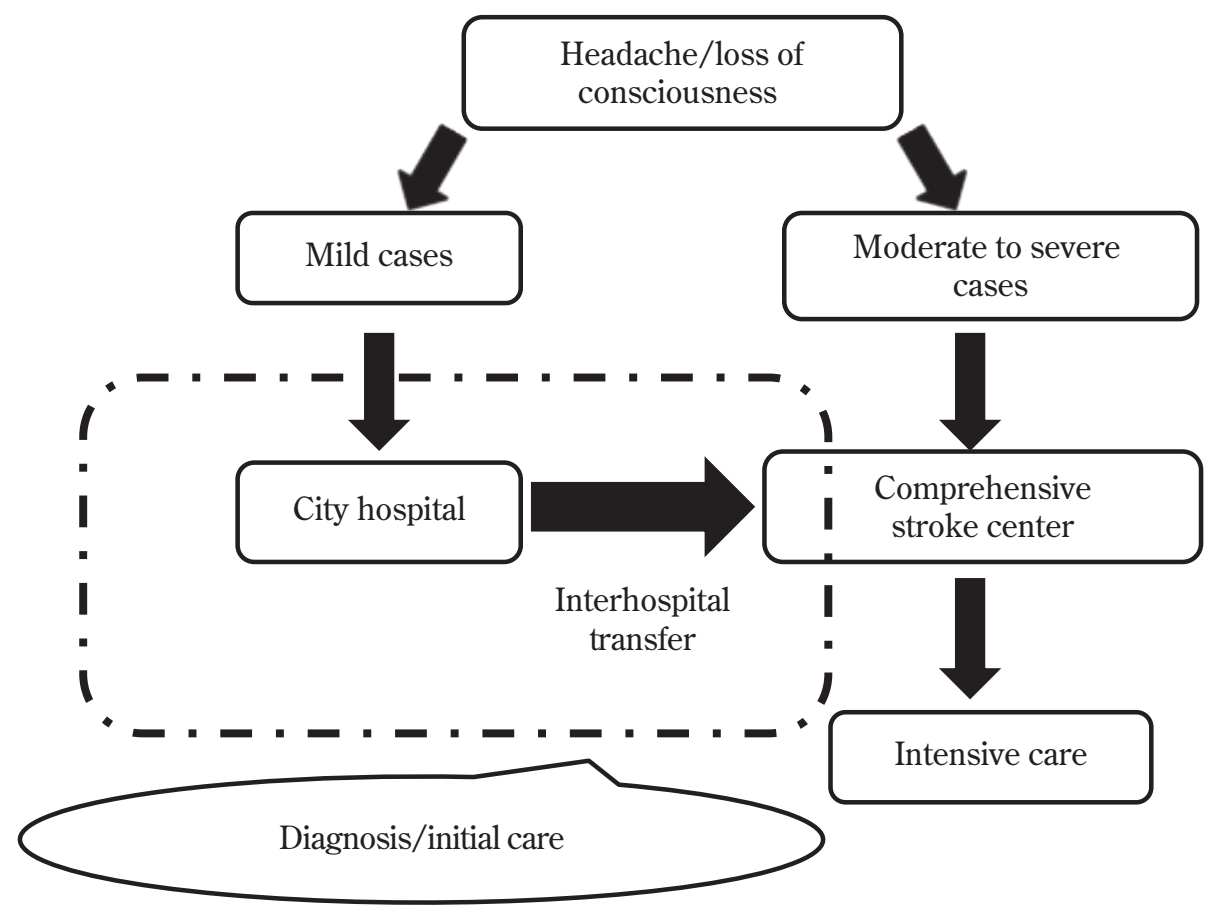

Fig. 2 Triage of patients with suspected of SAH in urban areas

せられる結果である。

一方初診時に頭部 CT が行われていたにもかかわらず SAH と診断されなかったケースも 151 例（26\%）にみら れた。 CTで診断が難しい SAH は，血腫が高吸収ではな く等吸収に描出されるもの（Fig. 4), 脳幹部の腹側のみ に血腫が限局するもの，大脳半球裂に限局するもの，高 位円蓋部の脳溝にのみ血腫がみられるものなどがあり, いずれも発症から数日経過した SAHに多い. 頭部 CT に

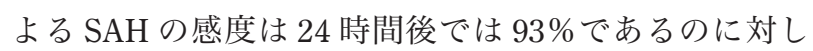
て，6 日後には57〜85\%に低下する ${ }^{5)}$. 頭痛の初発から 数日経っているケースでは特に慎重に CT を確認する必 要があり, CTで明らかに SAHの所見がみられなくても, 症状から SAH を疑う場合には, 腰椎穿刺や MRI まで行 わなければならない。これはAHA/ASA (American

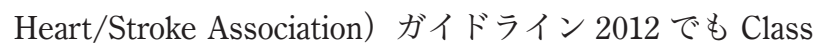
I Level B で推奨されている7)。腰椎穿刺はSAH に対す る最も鋭敏な検査法で血性髄液やキサントクロミーが SAH の特徵的な所見であるが, $20 \%$ 程度に腰椎穿刺時の 外傷による血液の混入（いわゆる traumatic tap）のため 疑陽性が生じ得る. MRI上 SAH は FLAIR (fluid attenuated inversion recovery）高信号として描出され，亜急性期の 診断には有用であるが, 超急性期では FLAIR 高信号とな らない可能性があるので注意が必要である。

\section{病院到着から外科治療までの SAH の初期治療}

脳動脈瘤の根治術に至るまでの再破裂予防としては, 降圧・鎮静・鎮痛などが知られているが, これらの有効 性を示すエビデンスや至適管理法についてのコンセンサ スは少ない。降圧に関しては, AHA/ASA ガイドライン 2012 では収縮期血圧 $160 \mathrm{mmHg}$ 以下を ${ }^{7)}$, ESO(European Stroke Organization）ガイドライン 2013 では $180 \mathrm{mmHg}$ 以下を推奨しているが22), これで再破裂を十分予防でき るかどうかは疑問である。脳灌流圧を維持するために は，血圧を下げ過ぎるのもよくないが，救急搬送されて きたばかりの SAH 患者の頭蓋内圧を知ることは不可能 である。日本の東北地方で行われた多施設共同研究で は，再出血例の多くが収縮期血圧 120１40 mmHg で

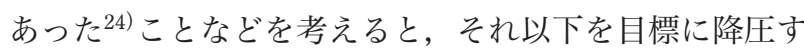
ることが妥当であろう。降圧を得るためには，鎮痛・鎮 静を積極的に行うことが推奨される。一般的にミダゾラ ム, ジアゼパムなどの minor tranquilizer やペンタジン・ フェンタニル・レミフェンタニルなどの麻薬もしくは麻 薬系鎮痛薬が用いられる。その際に注意すべきは舌根沈 下や呼吸抑制により却って血圧が上がったり，その後の 検査がスムースに行えなくなる点である，上記の問題を 避け，かつ安定した鎮静・降圧を得るために，プロポ 

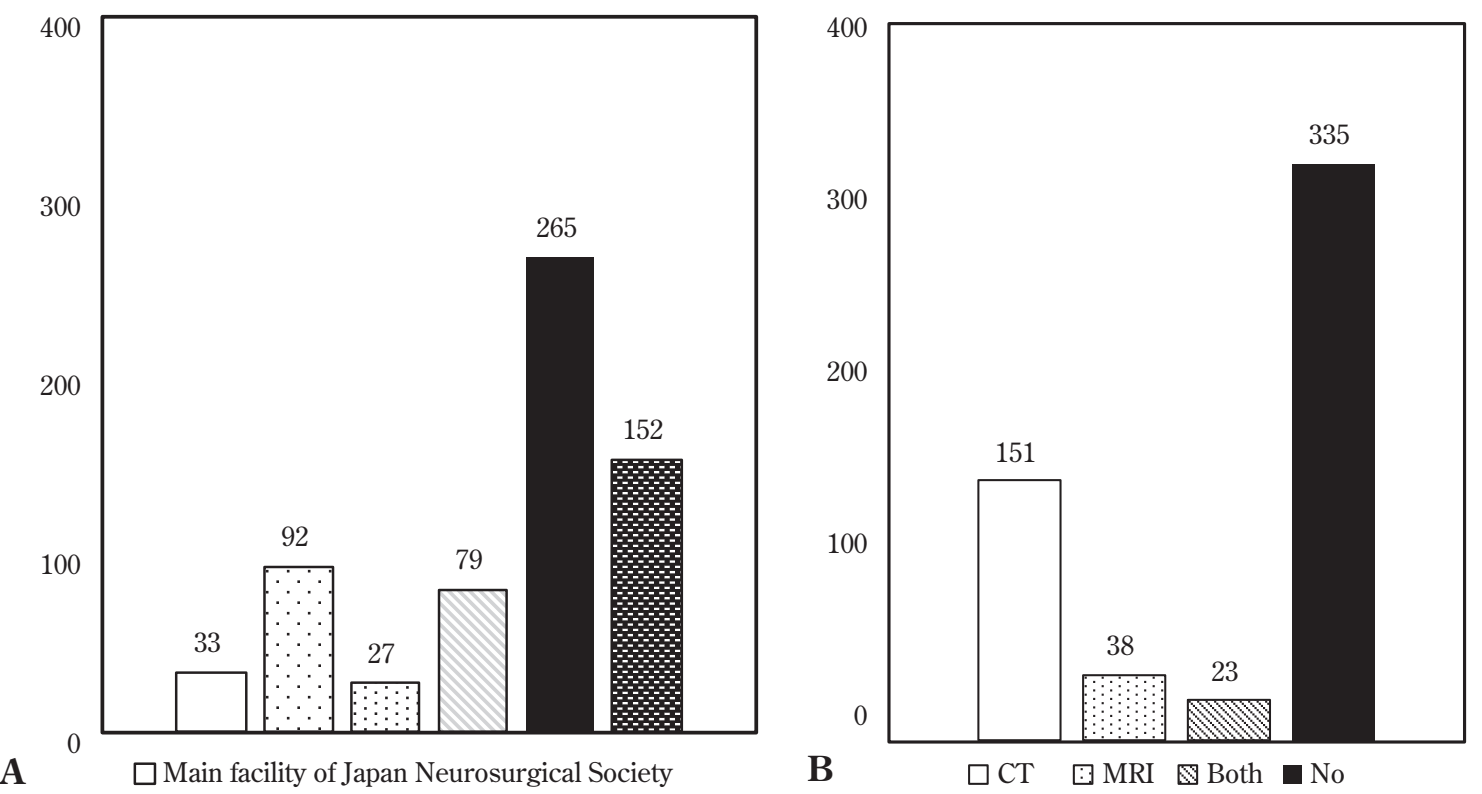

A $\square$ Main facility of Japan Neurosurgical Society

$\square$ Training facility of Japan Neurosurgical Society

$\square$ Related facility of Japan Neurosurgical Society

$\checkmark$ Training facility of Japan Stroke Society

- Private clinic

폴 Non-teaching hospital

Fig. 3 Initially missed or delayed diagnosis of SAH in a nationwide survey by the Japan Stroke Society

A : The classification of institutes that misdiagnosed SAH.

B : Neuroradiological assessment performed during the first visit for cases of SAH that were initially missed or those with a delayed SAH diagnosis.

The numerical values in the graphs are cited from the paper of Takagi Y. et al. ${ }^{23)}$
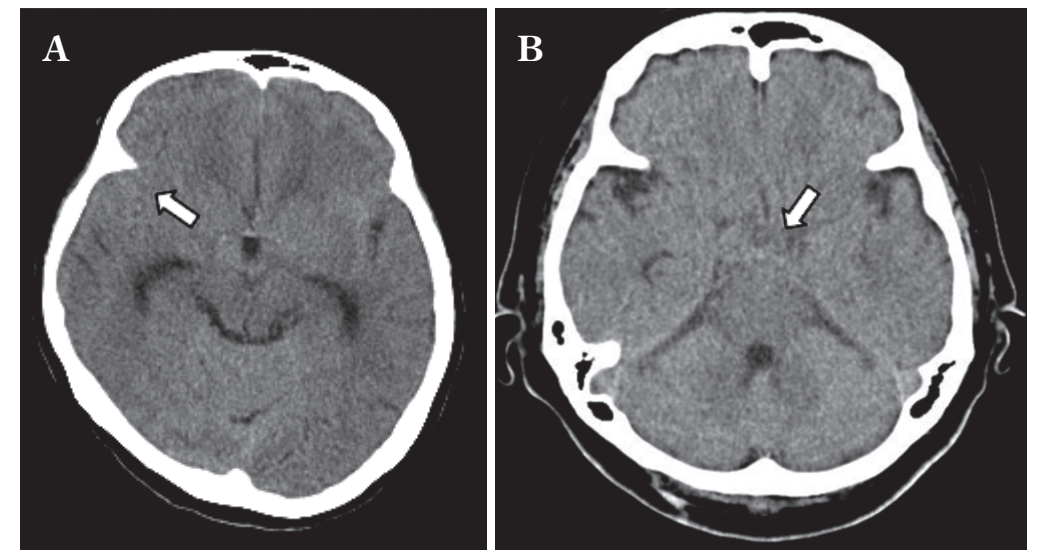

Fig. 4 CT findings of patients with SAH a few days after the onset

Arrows indicate an isodense SAH. 

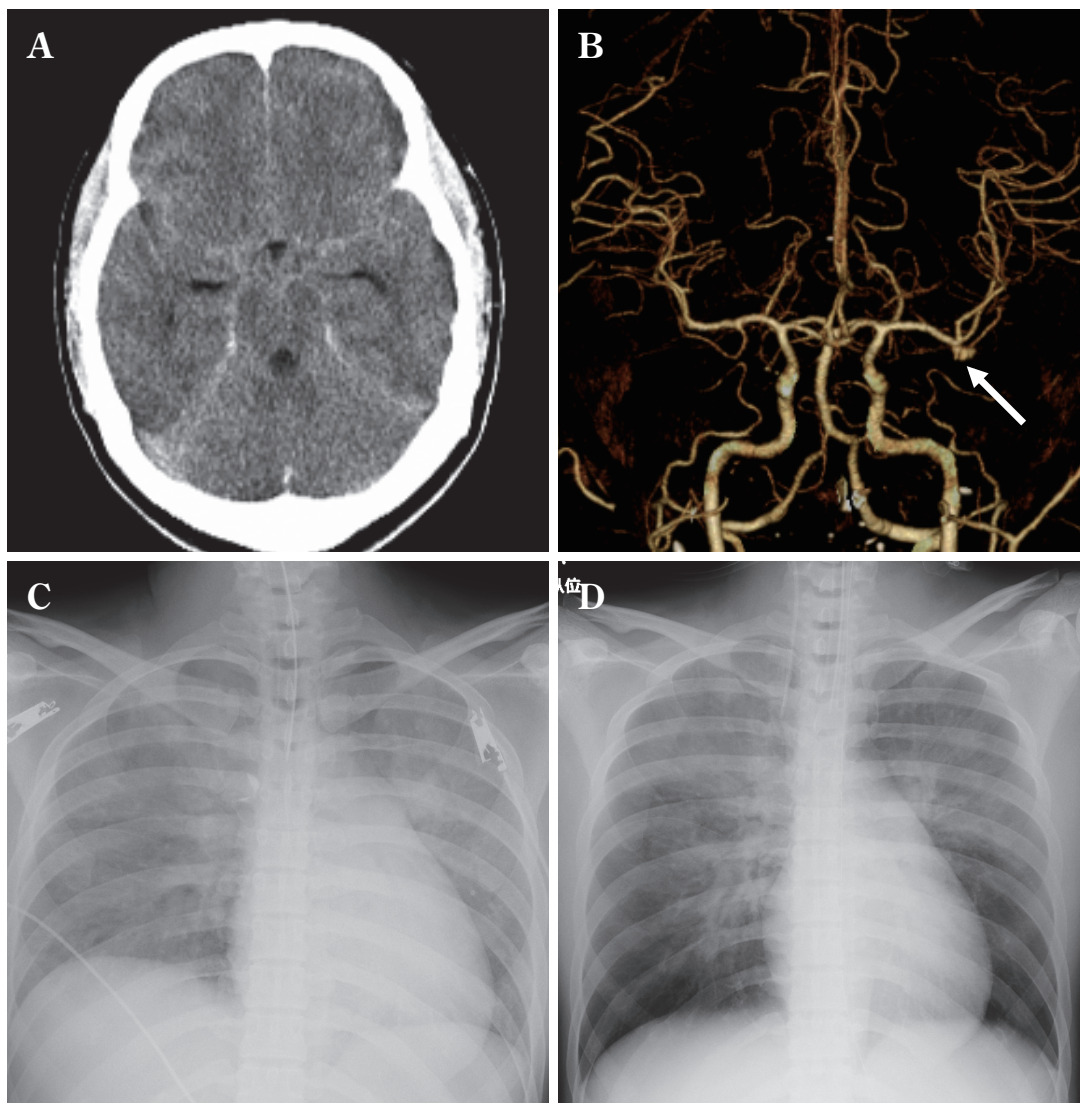

Fig. 5 Neurogenic pulmonary edema complicated with a poorgrade $\mathrm{SAH}$

A : CT scan revealing diffuse SAH.

B : CTA revealing a saccular aneurysm in the left MCA bifurcation (arrow).

C : Chest X-ray on admission showing severe pulmonary edema.

D : Chest X-ray 3 hours after the commencement of steroid administration and positive pressure breathing. Pulmonary edema was mitigated on the $\mathrm{X}$-ray and oxygenation of the patient was improved.

フォールなどの麻酔薬で全身麻酔の状態とし，気管内挿 管・人工呼吸器管理を行う施設も多い。この有効性を証 明するエビンスはなく, 神経症状の変化がわからなくな るという短所はあるが，その後の外科治療にスムースに 移行できるというメリットもある。

抗線溶剂であるトラネキサム酸の使用は，再出血の予 防に有効で，虚血性合併症を増やさないことが報告さ れ21)，AHA/ASA ガイドライン 2012 では推奨されてい る ${ }^{7)}$ が，2013 年のメ夕解析では虚血性合併症が増加する （相対危険度 1.41，95\%信頼区間 1.04 1.91） と報告され ている ${ }^{4)}$ ので，特に術中の血栓症が問題になる血管内治 療を行う症例での使用は控えたほうがよいであろう。

重症例では，頭蓋内圧の管理や心合併症の管理も重要 である. SAH急性期の急性水頭症に対して脳室ドレナー ジが再出血を誘発するかどうかについては，2007 年に Hellingman $ら^{11)}$ が年齢や発症時 grade などを match させ
たドレナージを行った群と行わなかった群の再出血率を 比較し, ドレナージ術によって再出血が助長されること はないという結果を報告した。また，術中にへパリンを 使用することが多い血管内治療においては，ドレナージ 術を先行させると血管内治療中に出血性合併症が生じる のではないかという懸念があるが，脳室ドレナージを 行ってからクリッピング術を行った群とコイリング術を 行った群（術中へパリン化）を比較した研究では, 両群 においてドレナージ術に起因する症候性・無症候性の出 血の頻度は変わらなかった ${ }^{13)}$. 脳室ドレーン留置によ り，血管内治療中の頭蓋内圧管理が可能となるし，万が 一の術中破裂の際にもドレーンが閉塞しなければ最悪の 事態を避けることができる，急性水頭症の際の脳室ドレ

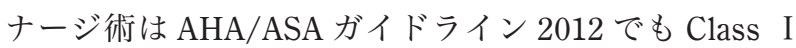
Level B で推奨されている7).

心肺合併症は重症 SAHに多く, 出血の際のカテコール 

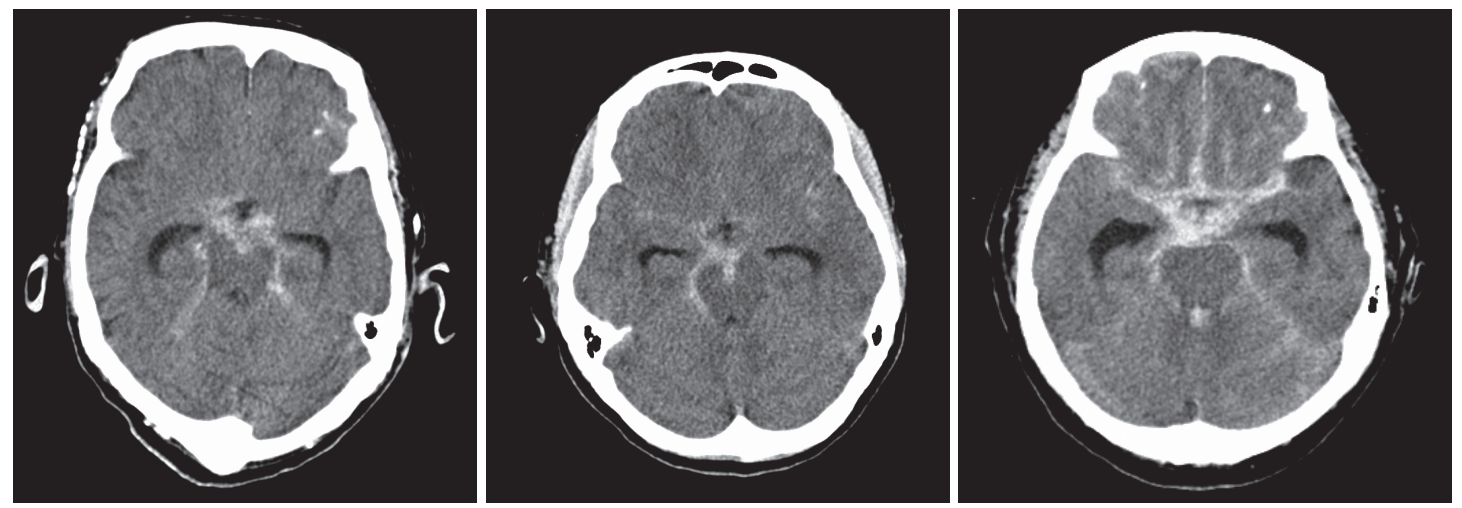

Non-perimesencephalic

Perimesencephalic

Fig. 6 Examples of CT scans in patients with SAH from an unknown origin

The localization of SAH differs among patients. The left one is similar to the perimesencephalic $\mathrm{SAH}$, whereas the right one is very different.

アミンサージが原因であるといわれている，特に，神経 原性肺水腫やたこつぼ型心筋症はバイタルサインの不安 定化をきたし，早期の外科治療を妨げるためすみやかな 対応が必要である. 代表症例を Fig. 5 に示す. 28 歳の女 性で, 来院時 Glasgow Coma Scale（GCS）E1V1M1の WFNS Grade V の SAH（Fig. 5A）で, CTA にて左中大脳 動脈に脳動脈瘤を認めた (Fig. 5B)。来院時の血圧は 84/ $42 \mathrm{mmHg}$ で, 来院後すぐに気管内挿管を行ったが $\mathrm{SpO}_{2}$ は $\mathrm{FiO}_{2} 1.0$ で $75 \%$ と著明な低酸素症を認めた。胸部 X 線 上にて神経原性肺水腫と診断し (Fig. 5C), 血圧が低值の ため利尿薬は投与できなかったが，ステロイド投与と PEEP $10 \mathrm{cmH}_{2} \mathrm{O}$ で陽圧換気を行った。それにより 3 時間 後には, $\mathrm{FiO}_{2} 0.4$ で $\mathrm{SpO}_{2}$ 100\%にまで酸素化は改善され た（Fig. 5D）。また来院時全胸部誘導で STの上昇を認 め, 心エコーで左室心基部の壁運動の低下が認められ た。この所見は典型的なたこつぼ型心筋症の所見ではな いため, 心臓カテーテル検查により冠動脈に有意狭窄が ないことを確認して, たこつぼ型心筋症の確定診断に 至った．来院当日は大量のカテコールアミン投与にて何 とか血圧を維持できる状況であったため脳動脈瘤に対す る根治術は断念したが, 翌朝にはカテコールアミン投与 下ではあるがバイタルが安定してきたため, クリッピン グ術を行った。術後意識レベルは徐々に改善し, 最終的 には軽度の記銘力障害のみを残して mRS 1 で退院と なった. 重症SAHにおける心肺合併症は時に致命的とな り救命困難であるが，その持続期間は急性期の比較的短 い時間であることが多い. 初期診療において適切な対応
を行い，外科的脳動脈瘤根治術にもっていくことができ れば，良好な予後を期待できることもあり，他科とも協 力して迅速に対応しなければならない.

\section{出血源の同定}

SAH と診断し, 初期治療で患者の状態を安定化させた らすみやかに出血源の同定を行う。出血源の同定には, 脳血管撮影（DSA）が gold standard として用いられてき たが，近年の 3D-CTA の画質向上に伴い，より低侵襲な CTA で出血源の脳動脈瘤の同定を行う施設が増えてき た. CTA は, 単純 CTで SAH を診断したその場で撮像す ることができるという大きな利点がある。一方, DSA は 動脈瘤自体や母血管・穿通枝の描出の感度が高く, 特に クリッピングかコイリングかの選択には有用である.

CTA の volume rendering 画像では broad neck でコイリン グに不向きと思われた脳動脈瘤が，DSAをするとそれほ ぞneckが広くなかったということはときどきある。また すべての穿通枝がDSA で描出できるわけではないが, 穿 通枝と動脈瘤の関係は治療選択に際して重要な判断材料 になる。これまでの報告でも, CTAのみで治療選択が可 能であった率は扮括む称 50〜80\%程度にとどまってい

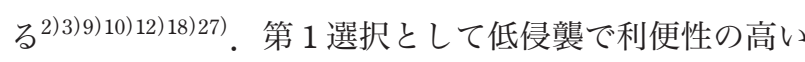
$\mathrm{CTA}$ を行うことに異論はないが, CTA のみでは的確な治 療選択を行えない症例があるため, その場合はDSAまで 行う必要がある. AHA/ASA ガイドライン 2012 では, ク リッピングかコイリングかの選択には DSA を行ったほ 
うがよいと記載されている (Class I Level B) ${ }^{7)}$.

初回 DSA で出血源が同定できないSAH は，10２0\% 存在する。基底槽やシルビウス裂にあまり血腫が存在せ ず，脳幹周囲にのみ血腫が存在する perimesencepalic type とそうでない non-perimesencephalic type では考え 方が異なり, Dalyai $ら^{8)}$ は, 前者は繰り返し DSA を行つ ても後日出血源が同定されたものはなかったが，後者で は $12.5 \%$ で後日出血源が同定されたと報告しており， perimesencephalic typeでは繰り返しの出血源精査は不必 要であると述べている。実際の臨床では両者に明確な区 別はない. Fig. 6 に示すCT はいずれも後日繰り返しの出 血源精査で出血源が同定されず，その後 SAHの再発もな かったいわゆる SAH from unknown origin の症例である が，SAHの分布は perimesencephalic type に近いものか ら通常の aneurysmal SAH を疑うものまでさまざまであ る。血腫が迁回槽や橋前槽のみに限局して厳密に perimesencephalic type といえるような症例は実際には少 なく，一般的には初回DSAで出血源が同定されなければ 繰り返しの出血源精査が推奨される.

\section{将来的展望}

SAH の急性期治療をスムースに行うためには，患者移 動の動線をできるだけ短くすることが重要である。初期 治療を救急外来で行い, SAH の診断を CT 室に移動して 行ってから, 再度追加の鎮静や全身麻酔導入などの処置 を病棟もしくは外来で行うことが多い。症候性の急性水 頭症の所見があれば手術室に移動して脳室ドレナージ術 を行い，その後血管撮影室に移動してDSAを行う. DSA で出血源である動脈溜が同定され，コイリングの方針に なればそのまま血管撮影室で治療を開始することができ るが，クリッピングの方針となれば，再度手術室に戻る ことになる。このような移動は医療従事者のみならず, 患者にもストレスを与える。この問題を解決するための 1 つの手段として，ハイブリッド手術室を利用した onestop-shop という考方方がある。 ハイブリッド手術室を 利用すれば, 単純 CT で SAH と診断された後のすべての 治療をそこで行うことができる。また，直達術と血管内 治療の複合治療を行わなければならない難治例の治療も 可能である。八イブリッド手術室自体も脳神経外科手術 の観点からはまだ完成形には遠く, 通常の血管撮影室と 同様にバイプレーンの透視下で高精細な血管内治療が可 能な透視装置とあらゆる脳神経外科手術の体位に対応可 能な手術台を併せもったシステムの開発など，今後さら なる発展の余地を残している。ハイブリッド手術室を用
いた one-stop-shop strategy が SAH 患者の予後改善に寄 与するかどうかは未知数であるが，今後発展が期待され る分野である。

また，遠隔地での画像診断データをITにより複数の基 幹病院に転送し，的確な搬送トリアージを行う telemedicine の発達も今後必要不可欠である.

脳神経外科では，ぞうしても手術手技や神経科学に注 目が集まってしまい, SAH の初期治療は陽のあたらない 地味な領域である。ただし，冒頭に述べたように SAHの 治療成績を左右する重要な分野であり, 現場の不断の努 力によりわが国の SAH 治療成績は諸外国と比較しても 高いレベルにある。この治療成績をさらに改善していく ためには，臨床現場の最前線での努力を継続するのに加 えて, 1 人でも多くの SAH 患者が再出血を起こすことな く出血源である動脈瘤の根治術を受けることができるよ う, 病院前治療ならびに病院到着後のシステムの最適 化・合理化も推進していかなければならない.

\section{COI 開示}

著者全員は日本脳神経外科学会への COI 自己申告の登録を 完了しています。

本論文に関して開示すべき COI はありません。

\section{文 献}

1) Abulhasan YB, Alabdulraheem N, Simoneau G, Angle MR, Teitelbaum J: Mortality after spontaneous subarachnoid hemorrhage : causality and validation of a prediction model. World Neurosurg 112: e799-e811, 2018.

2) Amagasaki K, Sato T, Kakizawa T, Shimizu T: Treatment of ruptured anterior circulation aneurysm based on computerized tomography angiography : surgical results and indications for additional digital subtraction angiography. J Clin Neurosci 9:22-29, 2002.

3) Anderson GB, Steinke DE, Petruk KC, Ashforth R, Findlay $\mathrm{JM}$ : Computed tomographic angiography versus digital subtraction angiography for the diagnosis and early treatment of ruptured intracranial aneurysms. Neurosurgery $45: 1315^{-}$ 1320 ; discussion 1320-1312, 1999.

4) Baharoglu MI, Germans MR, Rinkel GJ, Algra A, Vermeulen M, van Gijn J, Roos YB : Antifibrinolytic therapy for aneurysmal subarachnoid haemorrhage. Cochrane Database Syst Rev : CD001245, 2013.

5) Bederson JB, Connolly ES Jr, Batjer HH, Dacey RG, Dion JE, Diringer MN, Duldner JE Jr, Harbaugh RE, Patel AB, Rosenwasser RH ; American Heart Association : Guidelines for the management of aneurysmal subarachnoid hemorrhage : a statement for healthcare professionals from a special writing group of the Stroke Council, American Heart Association. Stroke 40:994-1025, 2009.

6) Boden WE, Eagle K, Granger CB : Reperfusion strategies in acute ST-segment elevation myocardial infarction : a comprehensive review of contemporary management options. $J$ Am Coll Cardiol 50: 917-929, 2007.

7) Connolly ES Jr, Rabinstein AA, Carhuapoma JR, Derdeyn CP, 
Dion J, Higashida RT, Hoh BL, Kirkness CJ, Naidech AM, Ogilvy CS, Patel AB, Thompson BG, Vespa P; American Heart Association Stroke Council ; Council on Cardiovascular Radiology and Intervention; Council on Cardiovascular Nursing ; Council on Cardiovascular Surgery and Anesthesia ; Council on Clinical Cardiology : Guidelines for the management of aneurysmal subarachnoid hemorrhage : a guideline for healthcare professionals from the American Heart Association/American Stroke Association. Stroke 43: 1711-1737, 2012.

8) Dalyai R, Chalouhi N, Theofanis T, Jabbour PM, Dumont AS, Gonzalez LF, Gordon DS, Thakkar V, Rosenwasser RH, Tjoumakaris SI : Subarachnoid hemorrhage with negative initial catheter angiography: a review of 254 cases evaluating patient clinical outcome and efficacy of short- and longterm repeat angiography. Neurosurgery $72: 646-652$; discussion 651-642, 2013.

9) Dehdashti AR, Rufenacht DA, Delavelle J, Reverdin A, de Tribolet N: Therapeutic decision and management of aneurysmal subarachnoid haemorrhage based on computed tomographic angiography. Br J Neurosurg 17:46-53, 2003.

10) Gonzalez-Darder JM, Pesudo-Martinez JV, Feliu-Tatay RA : Microsurgical management of cerebral aneurysms based in CT angiography with three-dimensional reconstruction (3D-CTA) and without preoperative cerebral angiography. Acta Neurochir (Wien) $143: 673-679,2001$.

11) Hellingman CA, van den Bergh WM, Beijer IS, van Dijk GW, Algra A, van Gijn J, Rinkel GJ : Risk of rebleeding after treatment of acute hydrocephalus in patients with aneurysmal subarachnoid hemorrhage. Stroke 38: 96-99, 2007.

12) Hoh BL, Cheung AC, Rabinov JD, Pryor JC, Carter BS, Ogilvy CS : Results of a prospective protocol of computed tomographic angiography in place of catheter angiography as the only diagnostic and pretreatment planning study for cerebral aneurysms by a combined neurovascular team. Neurosurgery 54:1329-1340; discussion 1340-1322, 2004.

13) Hoh BL, Nogueira RG, Ledezma CJ, Pryor JC, Ogilvy CS : Safety of heparinization for cerebral aneurysm coiling soon after external ventriculostomy drain placement. Neurosurgery 57:845-849; discussion 845-849, 2005.

14) Kowalski RG, Claassen J, Kreiter KT, Bates JE, Ostapkovich ND, Connolly ES, Mayer SA : Initial misdiagnosis and outcome after subarachnoid hemorrhage. JAMA 291:866869, 2004.

15) Naval NS, Chang T, Caserta F, Kowalski RG, Carhuapoma JR, Tamargo RJ : Impact of pattern of admission on outcomes after aneurysmal subarachnoid hemorrhage. J Crit Care 27 : 532 532.e1-532.e7, 2012.

16) Nieuwkamp DJ, Setz LE, Algra A, Linn FH, de Rooij NK, Rinkel GJ : Changes in case fatality of aneurysmal subarachnoid haemorrhage over time, according to age, sex, and region : a meta-analysis. Lancet Neurol $\quad 8: 635-642,2009$.

17) Nuno M, Patil CG, Lyden P, Drazin D : The effect of transfer and hospital volume in subarachnoid hemorrhage patients. Neurocrit Care 17:312-323, 2012.

18) Pechlivanis I, Schmieder K, Scholz M, Konig M, Heuser L,
Harders A : 3-Dimensional computed tomographic angiography for use of surgery planning in patients with intracranial aneurysms. Acta Neurochir (Wien) 147:1045-1053 ; discussion 1053, 2005.

19) Saver JL, Goyal M, van der Lugt A, Menon BK, Majoie CB, Dippel DW, Campbell BC, Nogueira RG, Demchuk AM, Tomasello A, Cardona P, Devlin TG, Frei DF, du Mesnil de Rochemont R, Berkhemer OA, Jovin TG, Siddiqui AH, van Zwam WH, Davis SM, Castano C, Sapkota BL, Fransen PS, Molina C, van Oostenbrugge RJ, Chamorro A, Lingsma H, Silver FL, Donnan GA, Shuaib A, Brown S, Stouch B, Mitchell PJ, Davalos A, Roos YB, Hill MD ; HERMES Collaborators: Time to treatment with endovascular thrombectomy and outcomes from ischemic stroke: A meta-analysis. JAMA 316: 1279-1288, 2016.

20) Schuss P, Hadjiathanasiou A, Borger V, Wispel C, Vatter H, Guresir E : Poor-grade aneurysmal subarachnoid hemorrhage : factors influencing functional outcome-A singlecenter series. World Neurosurg $85: 125-129,2016$.

21) Starke RM, Kim GH, Fernandez A, Komotar RJ, Hickman ZL, Otten ML, Ducruet AF, Kellner CP, Hahn DK, Chwajol M, Mayer SA, Connolly ES Jr : Impact of a protocol for acute antifibrinolytic therapy on aneurysm rebleeding after subarachnoid hemorrhage. Stroke 39:2617-2621, 2008.

22) Steiner T, Juvela S, Unterberg A, Jung C, Forsting M, Rinkel G ; European Stroke Organization : European Stroke Organization guidelines for the management of intracranial aneurysms and subarachnoid haemorrhage. Cerebrovasc Dis 35: 93-112, 2013.

23) Takagi Y, Hadeishi H, Mineharu Y, Yoshida K, Ogasawara K, Ogawa A, Miyamoto S : Initially missed or delayed diagnosis of subarachnoid hemorrhage: A nationwide survey of contributing factors and outcomes in Japan.J Stroke Cerebrovasc Dis 27: 871-877, 2018.

24) Tanno Y, Homma M, Oinuma M, Kodama N, Yamamoto T : Rebleeding from ruptured intracranial aneurysms in north eastern province of Japan. A cooperative study. J Neurol Sci 258: 11-16, 2007.

25) van Lieshout JH, Bruland I, Fischer I, Cornelius JF, Kamp MA, Turowski B, Tortora A, Steiger HJ, Petridis AK: Increased mortality of patients with aneurysmatic subarachnoid hemorrhage caused by prolonged transport time to a high-volume neurosurgical unit. Am J Emerg Med $35: 45^{-}$ 50, 2017.

26) Vermeulen MJ, Schull MJ : Missed diagnosis of subarachnoid hemorrhage in the emergency department. Stroke $\mathbf{3 8}$ : 1216-1221, 2007.

27) Westerlaan HE, Gravendeel J, Fiore D, Metzemaekers JD, Groen RJ, Mooij JJ, Oudkerk M : Multislice CT angiography in the selection of patients with ruptured intracranial aneurysms suitable for clipping or coiling. Neuroradiology 49 : 997-1007, 2007.

28) Wilson TJ, Saadeh Y, Stetler WR Jr, Pandey AS, Gemmete JJ, Chaudhary N, Thompson BG, Fletcher JJ : Transfer time to a high-volume center for patients with subarachnoid hemorrhage does not affect outcomes. J Stroke Cerebrovasc Dis 24: 416-423, 2015. 
くも膜下出血に対する初期治療の現状と問題点

片岡 大治 中川 俊祐 高橋 淳高木 康志 宮本 享

くも膜下出血（SAH）はいまだに死亡率 25～50\%と予後不良の疾患であり, 再破裂が予後に大きく 影響を及ぼすため, 早期診断と適切な初期治療が重要である. 診断の遅れは, 画像検查の未施行, CT でのSAH の見逃しなどで生じ，ときとして致命的な転帰を辿る. 単純 CT で診断が難しいケースで は, MRI・腰椎穿刺まで行うことが求められる. 初期治療では再破裂予防のため鎮痛・鎮静・降圧を 図るが，至適降圧目標值や鎮静プロトコールについてのコンセンサスは定まっていない，重症例で は, 頭蓋内圧の管理や心血管系合併症の治療も必要で, 急性水頭症があれば脳室ドレナージを行うこ とが推奨される. 最近では, 3D-CTA が出血源の同定に用いられることが多いが, 直達術か血管内治 療かの選択には, 3D-DSA のほうが有用性が高い.

脳外誌 $28 ： 542-551,2019$ 